\title{
Organizational Communication and Web Site Design
}

\author{
Thea van der Geest \\ University of Twente, The Netherlands \\ t.m.vandergeest@wmw.utwente.nl
}

This paper reports findings of a case study of web sites. The seven sites included in this report are described on the basis of the objectives the organizations had with it and the interaction they wanted with their visitors. All organizations offer their web site visitors more than just a hyperlinked version of their print materials. The most common expansion is to give direct access to the organization, but the sites are also used to create a community of users. Although all sites are intended to serve multiple audiences, it is left to the user to find the appropriate information for the particular target group they belong to.

\section{Introduction}

The World Wide Web and e-mail are the two applications that have made the Internet viable as a means of communication. A few years ago, offering and retrieving information over the Internet was awkward. But the Web, and such browsers as Netscape and Internet Explorer, created a general interface that supports the various actions users might want to perform, independent of the actual type of program or machine the information was created with or stored on. As users we now can perform actions such as reading a document that is stored on a distant computer, switching to a related document at another distant computer, having that distant computer send us a particular set of files, and having it execute little programs, without worrying how those distant computers were programmed to perform these actions for us.

The incredible growth in numbers of users of the Internet shows that this ease of use has not been lost on the broad public. No longer is the Internet a playground that is accessible only for the "guys of the gang", those initiated in the secret language and code of conduct, who own the territory and don't want to share their toys with others. Especially in the United States, all kinds of organizations have embraced the Web as a means to target their audiences. You will find a URL on the package that contains your kid's Happy Meal; you will see one broadcast during or after your favorite television show so you can look up extra information on the performers; you can sell your used car on your newspaper's web site; you can check the view from the seat in the baseball stadium you plan to buy a ticket for. People can now do all of these ordinary things on the Web, and more.

When ordinary people start using the Web for ordinary things, ordinary professional communicators can no longer avoid considering the Web as one of their options when planning and designing the communication for their organization. But what exactly needs to be considered when you are thinking about the Web as a channel of communication? What kinds of decisions have organizations made when they decided to 
use the Web? How did they translate these decisions into pages, texts and images? To answer those questions I conducted a series of case studies in organizations that have been using the Web as one of their channels of communication already for some time.

In this paper I will focus on three themes in the case studies. First, the organizations as the initiators of the communication: why did they consider to use the web, and what factors influenced the initial design? Secondly, the web site produced will be characterized in terms of the facilities for communication with audiences. Thirdly, I will focus on the audiences the organizations are aiming at and how they adapt their web sites to the various target groups. Each of the three sections conclude with remarks that should be helpful for prospective designers of web sites and pages. But first I will shortly introduce the approach of the study.

\section{Approach of the study}

The cases (organizations and their web sites) were selected to cover a wide range of uses of the Web. The sites and pages included had various communicative functions (e.g. informative, persuasive, instructional) and modes of presentation (text, visuals, audio, video). They can be made by individuals or by teams of up to twenty people, by business companies or by public agencies. They contained content on widely diverse topics, such as the launch of a new software product, a declaration of a state's governor, or the game scores of a national baseball team.

If the owners of the site agreed, I conducted a pre-structured interview of 1-1.5 hours with two people, one being a person who was responsible at the managerial level, the other being someone who had been involved in the actual production of the pages, such as the manager of the production team or the editor of the pages. I interviewed them about their organization's communication policy and how it was effectuated in the web site. We also talked about the communication they wanted to achieve by means of the web site and how they assessed their success.

Since data collection is still in progress, this paper focuses on seven web sites out of the ten studied. In table $1 \mathrm{I}$ refer to the web sites with an indication of their content rather than with the name of the organization, since some of the selections represent only a small part of the complete set of sites and pages that has been set up by the organization. The URLs of the sites discussed can be found in the footnotes.

\section{Reasons to use the Web}

I started the interviews by asking how the organization decided whether to use the web as part of their communication with external audiences. It may be obvious that all organizations wanted to reach out to a broad range of audiences, otherwise they wouldn't have bothered to start a web site in the first place. However, under close examination it appears that there were large differences between the organizations. Two extremes were the Internet Bookstore and the Traffic Flow web site.

For the Internet Bookstore, communication with the customers is essential for success, and their web site is in the center of that communication. This site is where the customers go to browse, read reviews of books, buy them and pay, and track the shipping 
of the books ordered. Other means of communication are in place besides the web site, such as e-mail that is sent to customers to confirm orders or to draw their attention to new books that might fit their interests. But, for the customer, the web site simply IS the bookstore. The availability of the Web actually initiated the bookstore: one of the founders is a business analyst, who saw a market opportunity in the incredible growth of the Internet. The founders decided that books were a commodity that would sell well via the web. In this case, the communication between the organization and its primary target group, the customers, is built upon and around the web site.

In contrast, for the traffic engineers who created the Traffic Flow site, web use came almost as an afterthought. The state's Department of Transportation (DOT) collects images of traffic flow with cameras mounted at places along the freeways. The information is processed by operators in a dedicated computer system; it is used to optimize the traffic flow in order to reduce congestion on the overcrowded roads. For a number of years the DOT has allowed some customers, such as newspapers, radio stations and larger companies, to hook into their computer system and publish the data.

When the traffic engineers became aware of the potential of the internet, they thought that publishing the traffic data on a web site might reduce the workload of supporting the troublesome information delivery by modem to the not too computer-savvy radio stations. They had not fully realized that using the web to make the data accessible for their customers implied that it was accessible for a much more general public, such as the commuters themselves. The traffic engineers who maintain the web site now are becoming aware that new audiences also require new forms of communication. For example, part of the information, such as the bulletins on traffic incidents, is formatted in a DOT-originated lingo of abbreviations and road numbers. This never was a problem until incidental users became part of the audience.

Now the traffic engineers try to meet both the demands of their traffic management job and the needs of the expanding groups of ordinary commuters. They realize that the web site unexpectedly has made their agency visible in a positive way and they can show tax payers how their tax dollars are put to work. Nevertheless, web site design or maintenance is in nobody's job description, although one of the traffic engineers is allowed to spend quite a bit of time on it.

Between these two extremes, the web site as the core of an internet merchant site and the web site as a venue for publishing data that were collected for another purpose, one can find the other web sites studied. The interviewees mentioned the four following factors as influencing the initial design decisions, once it was decided to make a web site. The objectives of the site. Is it essential for the core goals of the organization? Must it reduce costs of other means of communication or replace those? Is it part of a clear business or communication policy? Or is it a try-out of a new technology by some people who love to tinker with it? Or a showcase for the organization's leading edge with new media?

The content of the site. Is the content generated for the site? Are the content production team and the technical production team of the site working together closely? Or is 
existing material recycled into the new medium? And is content production happening separately from the actual site design?

Previous and parallel systems. Is there a previous electronic system that is now abandoned for a web site? What were the experiences with that system? Does the organization have parallel systems to distribute the same information by other means? Who was or is responsible for the other systems' content production and maintenance?

The organizational culture. Who decides what is to be found on the various pages? Has the decision to use the web been made by superiors, to be executed by others? Or was it a grassroots development by individuals or groups within the organization? Does the organization allow various groups to present themselves autonomously? Or does it prescribe organizational guidelines and style handbooks? How does the web site fit in with other means of communication? Do groups within the organization have objections against the web? Against the producers within the organization? What are the constraints for production?

When these questions are answered for a particular web site, the designer has a good view of context factors that determine the initial design of the site.

\section{Designing communication}

Designing a web site is designing the communication with the visitor, in as far as it is to take place by means of the web site. The designer of the web site defines the range of activities and the extent of the actions the visitor can execute at the site, including the interaction that is going to take place between the organization that owns the site and the visitor. For example, only when a site provides an e-mail form, can the visitor send an open format response to the site owner by means of the web site. I asked the respondents to explain their organization's communication policy and to describe how the web site fit into it.

We have not yet developed an accepted terminology to talk about web sites as a communication means, with terms for "web genres", terms that would characterize parts of a web site by implying the functions, the audiences and their intended responses, and the arrangement, style and presentation of the content. Due lack of such a terminology, I characterize the sites here by showing the extent of user interaction that the organizations provided for in their web sites. The term "user interaction" has a somewhat broader meaning than the often used term "interactivity".

Interactivity in a multimedia product requires that: " ... the user, not the designer, controls the sequence, the pace, and most importantly, what to look at and what to ignore." (Kristof \& Satran, 1995, p. 35) . According to this definition, interactivity describes the type of interaction that will take place between the visitor and the web site. But the visitor might also interact with the people behind the web site, or via the web site with other visitors. Hence I use the broader term "user interaction" for the range of communication activities the site will allow the visitor to execute.

I saw six types of user interaction on the pages selected, and they seem to be the fundamental kinds of user interaction that are currently found on the World Wide Web. 


\section{Selecting}

Information is presented in pages that contain text, images or sound; visitors are supposed to scroll or click on hyperlinks to read, look or listen.

2. Activating

Information units are hidden behind "buttons"; visitors are supposed to click those to activate a linear sequence within the page. The button might, for example, activate an animation or demo, start an audio or video player, or download a file or program.

3. Pre-formatted communication with the site owner

The site requests non-automated but pre-formatted input from the visitor; for example, visitors have to fill out a form, answer closed-form questions, or select items from a catalogue in order to conduct a transaction via the web site.

4. Unstructured communication with the site owner

The site offers a link (mostly an e-mail form) to the webmaster or to the owner of the information presented; visitors can send non-automated, non-formatted messages on any subject they want to communicate about directly to the persons responsible for the site.

5. Unstructured communication with other users

The site offers a link (mostly an e-mail form) to other visitors of the site; visitors can send non-automated, non-formatted messages on any subject directly. The web site creates a forum for visitors.

6. Unstructured communication with other users, in real time

The site offers a direct, real-time channel for interaction with other visitors of the site, for example a chat facility where visitors can exchange non-automated, non-formatted messages on any subject with other visitors of the site directly, and get responses immediately.

Table 1 describes the range of user interaction the organizations allowed visitors of their web site. 


\begin{tabular}{|c|c|c|c|c|c|c|}
\hline $\begin{array}{l}\text { Type of } \\
\text { interaction }\end{array}$ & Selecting & Activating & $\begin{array}{l}\text { Preformatted } \\
\text { com- } \\
\text { munication }\end{array}$ & $\begin{array}{l}\text { Unstructured } \\
\text { com- } \\
\text { munication } \\
\text { with owner }\end{array}$ & $\begin{array}{l}\text { Unstructured } \\
\text { com- } \\
\text { munication } \\
\text { with other } \\
\text { visitors }\end{array}$ & $\begin{array}{l}\text { Unstructured, } \\
\text { real-time com- } \\
\text { munication }\end{array}$ \\
\hline $\begin{array}{l}\text { Year of } \\
\text { Reader }^{1}\end{array}$ & + & - & - & + & - & - \\
\hline $\begin{array}{l}\text { Nature } \\
\text { Conservation } \\
2\end{array}$ & + & + & + & - & - & - \\
\hline $\begin{array}{l}\text { Electronic } \\
\text { City Hall }\end{array}$ & + & + & - & + & - & - \\
\hline Univeristy $^{4}$ & + & + & + & + & - & - \\
\hline Traffic Flow & + & - & - & + & - & - \\
\hline $\begin{array}{l}\text { Professional } \\
\text { baseball club }\end{array}$ & + & + & + & + & + & + \\
\hline $\begin{array}{l}\text { Internet } \\
\text { bookstore }^{7}\end{array}$ & + & - & + & + & + & - \\
\hline
\end{tabular}

\section{Table 1: selected sites, characterized on basis of intended user interaction}

The table demonstrates that the organizations offer their visitors not just a clickable, hyperlinked version of their reading materials. They all have chosen to expand the range of interaction they provide for their visitors. The most common expansion is giving direct access to the organization by providing an e-mail form, often accompanied by an explicit request for feedback on the site and its content. Most likely the web master or the producer of the page is the one the email is actually sent to, even when it would be more appropriate to send the mail to the provider of the content. Some of the sites generated so many reactions that the organizations are starting to make "responding to the email of web site visitors" a new function in their communication or customer service department.

Although it would have fit in the communication policy of at least three more organizations, only two sites directly support the interaction between visitors. The Baseball Club has both a forum and a chat room for fans and the Internet Bookstore provides a forum for book readers. The latter asks its customers to send in reviews, that are automatically displayed along with the titles reviewed. Other customers respond to the reviews, and thus create the electronic version of a book circle where readers discuss

\footnotetext{
${ }^{1}$ http://cisl.ospi.wednet.edu

${ }^{2}$ http://www.tnc-washington.org

${ }^{3} \mathrm{http}: / /$ www.ci.seattle.wa.us

${ }^{4}$ http://www.washington.edu

${ }^{5}$ http://www.wsdot.wa.gov.regions/northwest/nwflow

${ }^{6}$ http://www.mariners.org

$7 \mathrm{http} / /$ www.amazon.com
} 
the books they have read. The user interaction at the web site is in line with the organization's communication policy: they want an open, informal contact with their prospective book buyers, and give them plenty of reasons to visit and re-visit parts of the site. They expect it will pay off in terms of book sales.

Potential book buyers will have a pleasant time reading about books they are interested in, get better information about the books they are considering buying, will be more satisfied with their purchase, and hence will be more likely to spend time and money again in the Internet bookstore. This is an exemplary use of communication facilities that fit within important organizational goals.

A careful design of the web site, guided by considerations about the interaction the organization would like to establish with or between visitors, can create a very powerful means of communication. Several respondents even volunteered their opinion that this was the major benefit of the web, compared to other means of communications. However, it is obviously not enough to put in chat rooms, user forums or e-mail forms, just because they are possible and trendy. If those types of user interaction are not backed up by the organization, they are likely to dwindle by the time the novelty wears off.

The design of the site should include the design of the back-end, such as a procedure for handling visitor's e-mail, or requiring famous baseball players to take part in the on-line chats from time to time. In the end, designing the organization's web site can well lead to re-designing other organizational processes, such as revising the baseball players' contracts to include such promotional activities.

\section{Adapting to multiple audiences}

It is often assumed that the Web, as opposed to print media, makes it easier and more feasible to accommodate various audiences at the same time. This clearly was an argument for the organizations studied to initiate web use. Six out of seven web sites had clearly discernible target groups, according to the respondents. But that does not mean that all of them indeed provided guidance for their varied audiences. For example, the web site on The Year of the Reader initiative of the State of Washington was meant for teachers and librarians, parents and other caretakers, community members such as business leaders, and kids.

These are very distinct audiences who will come to the web site with widely varying interests, previous knowledge and expertise. The teachers might want to know about initiatives in other schools or to download sample materials, whereas parents and kids might be looking for home activities and lists of books for specific reading-skill levels. The web site contained an appeal to business leaders to get involved with the Year of the Reader initiative. Businesses probably are interested in ways to integrate it into their organization, while at the same time benefiting their business interests. The Year of the Reader web site indeed contained information for all of its target groups, but it was up to the reader to find out what information was meant to address his or her interests.

The Year of the Reader web site was not an exception. The visitors of almost all sites were supplied with very few cues other than content headings about information that was 
useful for them. One of the few exceptions is the Electronic City Hall. In a major redesign of the site, after a year of running, the producers decided to group the content around three major target groups, Visitors, Citizens and Businesses. These groups are identified on the home page, and reinforced with buttons and links throughout the site. At the same time, in the "Tips" page which is accessible directly from the home page, the producers assure their three target groups that they will not miss important information. They write:

".. this site is divided into three major sections tailored to three types of audiences. Many of the links to documents on this site appear in more than one section so you don't have to worry about exploring the other sections unless you consider yourself also a part of those audiences." (http://www.ci.seattle.wa.us/html/help.htm, May 1997)

This thoughtful approach is even more remarkable given the fact that the information in the site is provided by numerous different public and private agencies and services. The approach the designers of the Electronic City Hall have chosen is worth copying by others who face a similar problem. They made the various information suppliers responsible for delivering the information HTML -coded, and provided training and templates to support them. But they kept the arrangement of the content and the access features such as buttons and tables of content to themselves, ensuring that the various users were guided to the chunks of information in a consistent way. Although the site is inconsistent at the lower level, displaying information in many styles and formats, the users are not confronted with the inconsistency as long as they are searching rather than browsing. And that is what at least two target groups (citizens and businesses) probably will do.

Often it is not simple for organizations to predict what their audiences will be, once their web site is up and running. Almost all interviewees mentioned occurrences of unexpected visitors to their site. The owners of the Baseball site, for example, found out that foreign fans often missed current game information because their radio or TV stations did not broadcast the games. These visitors started to use the site particularly during games, because a continuously updated game log gave them a streaming account of the match. The baseball club decided to try out web-radio reports of the game. The home page of the University, which shows a camera view on a central plaza on campus, was used by people to wave to friends abroad or to check the weather in Seattle. The producers added current weather information.

Once the site owners or producers are aware of the expected and unexpected visitors their site attracts, it becomes easier to design or adapt the site for those groups. The selected sites that did address different target groups other than with content cues, only did so after they had learned about their visitor population and did a major redesign for the site on the basis of that information. It might make sense for organizations to plan a yearly update of any web site on the basis of findings about actual users, use and effects of the web pages.

\section{Conclusion}

Interviews with web site owners and developers showed that their sites were more than just a brochure or catalogue in its electronic form. Initial design decisions seem to be influenced by the organizations' objectives and structure and by previous experiences 
with other media rather than by the potential of the technology. The organizations studied used their sites to create or expand their range of interaction facilities with their target groups. In most cases they used them for giving the visitor direct access to the organization's representatives in a way that was not in place beforehand. But the arrangement of content and the navigation within the site did not reflect this preoccupation with giving visitors good access. In most cases it was up to the visitors to determine which information was particularly useful for the various target groups. This might be caused by the novelty of the medium and its still unpredictable effects. Therefore, my advice is to plan iterative evaluation and redesign as a systematic part of the web site design cycle. Time and resources should be set apart for collecting data about the use and appreciation of the site and for executing major redesigns on the basis of the evaluation findings.

\section{References}

Kristof, R., and Satran, A., Interactivity by design. Creating \& Communicating with New Media. Indianapolis: Hayden, 1995 